[white paper]

Diamond Open Access

\title{
Física do espaço-tempo
}

\author{
Colaboração Física Aberta ${ }^{1}$ \\ 26 de Junho de 2021
}

\begin{abstract}
Resumo
Neste white paper, disponibilizo diretrizes sobre um material de apoio para o estudo da relatividade especial (ou restrita).
\end{abstract}

palavras-chave: teoria da relatividade especial ou restrita, espaço-tempo plano

A versão mais atualizada deste artigo está disponível em https://osf.io/afuzc/download https://zenodo.org/record/5034783

\section{Introdução}

1. Existem excelentes livros de divulgação científica e ótimos livros técnicos que explicam a teoria da relatividade especial (TRE).

2. Na maioria das vezes, os livros técnicos apresentam a TRE com notação matemática rebuscada, o que é bom para quem entende a física subjacente, mas é ruim para os leitores iniciantes no assunto.

3. O livro Spacetime Physics [1] é uma excelente referência que preenche a lacuna que existe entre a divulgação científica e a parte técnica especializada.

${ }^{1}$ Todos os autores com suas afiliações aparecem no final deste artigo. 
4. [1] está disponível sob a licença Creative Commons, podendo ser baixado gratuitamente na internet e seu conteúdo pode ser adaptado e redistribuído, seguindo a licença em questão [2].

5. O objetivo deste white paper é apresentar um material didático baseado em [1], que possa ser utilizado tanto por mentes curiosas, como por professores que queiram ministrar cursos introdutórios de relatividade.

\section{Download}

6. O arquivo ZIP, contendo todos os recursos digitais descritos a seguir, está disponível em https://osf .io/xnmcr.

\section{Textos}

7. Preâmbulo

Contém dicas e orientações importantes para o estudo.

8. Plano de Ensino

Documento auxiliar a ser utilizado pelos professores para guiá-los na condução do curso.

9. Carta de Hermann

Carta escrita pelo pai de Einstein em 13 de abril de 1901.

10. Tempo de Newton

Texto comentando sobre o caráter absoluto do tempo na física newtoniana.

11. Parábola dos Exploradores

Uma interessante parábola acerca de medições de terras e que guarda uma analogia interessante com o assunto abordado.

12. Capítulos

Discussão sobre os capítulos 1 a 5 do livro [1]. 
13. Exercícios

Resolução de praticamente todos os exercícios do livro [1].

\section{Áudios}

14. Narração dos textos.

\section{Notas escritas à mão}

15. As notas contêm um resumo de todo o conteúdo apresentado nos textos.

\section{Licença}

16. Este material está licenciado sob Creative Commons [2].

\section{Considerações Finais}

17. Espero que este material possa ser útil para os apaixonados em conhecer os mistérios do nosso espaço-tempo, bem como para os professores que desejam ministrar cursos sobre o tema.

\section{Ciência Aberta}

$\mathrm{O}$ arquivo latex para este artigo, juntamente com outros arquivos suplementares, estão disponíveis em [3]. Seja coautor(a) deste artigo, envie sua contribuição para mplobo@uft.edu.br.

\section{Consentimento}

O autor concorda com [4]. 


\section{Como citar este artigo?}

https://doi.org/10.31219/osf.io/afuzc

https://zenodo.org/record/5034783

\section{Referências}

[1] Taylor, Edwin F., Edwin F. Taylor, and John Archibald Wheeler. Spacetime physics. https://eftaylor.com/spacetimephysics

[2] CC. Creative Commons. Attribution 4.0 International (CC BY 4.0). https://creativecommons.org/licenses/by/4.0

[3] Lobo, Matheus P. "Open Journal of Mathematics and Physics (OJMP)." OSF, 21 Apr. 2020.

https://doi.org/10.17605/osf.io/6hzyp

[4] Lobo, Matheus P. "Simple Guidelines for Authors: Open Journal of Mathematics and Physics." OSF Preprints, 15 Nov. 2019.

https://doi.org/10.31219/osf.io/fk836

\section{Colaboração Física Aberta}

Matheus Pereira Lobo (autor principal, mplobo@uft.edu.br) $)^{1,2}$ https://orcid.org/0000-0003-4554-1372

${ }^{1}$ Universidade Federal do Tocantins (Brasil)

${ }^{2}$ Universidade Aberta (UAb, Portugal) 